Int. J. Odontostomat., 10(2):267-276, 2016.

\title{
Ethanol-Wet Bonding Technique: 18-month Clinical Evaluation
}

\author{
Técnica de Adhesión Húmeda en Etanol: Evaluación Clínica a los 18 Meses
}

\begin{abstract}
Thaís Andrade De Figueiredo Barros*; Joyce Figueira Da Araújo*; Esther Marina França Braga ${ }^{\star \star *}$; Patricia de Almeida Rodrigues Silva e Souza ${ }^{* * *}$; Sandro Cordeiro Loretto ${ }^{* * * *}$ \& Mário Honorato Silva E Souza Júnior ${ }^{* * * *}$
\end{abstract}

BARROS, T. A. F.; DA ARAÚJO, J. F.; BRAGA, E. M. F.; SILVA E SOUZA, R. P. A.; LORETTO, S. C. \& SOUZA JÚNIOR, M. H. S. Ethanol-wet bonding technique: 18-month clinical evaluation. Int. J. Odontostomat., 10(2):267-276, 2016.

ABSTRACT: The objective of this randomized clinical trial was to evaluate the clinical performance up to 18 months of restorations placed using ethanol-wet bonding technique (EWBT) compared with the three-step etch-and-rinse (TSER) and one-step self-etching (OSSE) approaches. Ninety-three non-carious cervical lesions (31 for each group) were restored by one experienced operator in 17 patients under relatively dry conditions using gingival retraction cord, cotton rolls and saliva ejector. Each adhesive system was randomly allocated to one of randomized cervical lesions until the three groups were present in the same subject in equal amounts. The restorations were evaluated at baseline, 6,12 and 18 months by two blinded and calibrated examiners using the modified US Public Health Service guidelines (USPHS) for the following outcomes: retention (kappa=1.00), staining and marginal adaptation (kappa=0.81) and analyzed by Fisher's exact and Kruskal-Wallis tests, respectively. No significant differences were observed among groups after 18 months for any of the assessed criteria ( $p>0.05)$. The intra-group analysis performed by Cochran's test (for retention) and Wilcoxon test (for marginal adaptation/staining) revealed significant differences between the time intervals baseline/18 months in marginal adaptation $(p=0.0117)$ and retention $(p=0.0101)$ for OSSE and in marginal staining for TSER $(0.0051)$ and EWBT $(p=$ 0.0277 ) groups. The survival analysis for retention criteria and the overall clinical success were performed using a log-rank test and did not show significant differences among groups $(p>0.05)$. All three adhesives protocols presented similar clinical performance up to 18 months.

KEY WORDS: dentin, dentin-bonding agents, randomized controlled trial.

\section{INTRODUCTION}

The most cited reasons for failure of adhesive restorations are loss of retention and marginal adaptation (De Munk et al., 2005). Hence, several researches seek a way to improve the stability ofresin-dentin bond.

The dentin-wet bonding technique introduced to prevent demineralized dentin to collapse led manufactures to add increasing concentrations of hydrophilic monomers to their proprietary adhesive systems. As a result, very hydrophilic polymers were produced, and they could absorb $5 \%$ to $12 \%$ of water (Hosaka et al., 2009). Such a phenomenon contributed to a progressive decreasing in the mechanical properties of the adhesive interface (Sadek et al., 2007a, 2010a; Sauro et al., 2009a).

The hybrid layer produced behaves as a permeable structure and seems to be susceptible to water hydrolysis and the plasticizing effect (De Munk et al.; Hosaka et al.; Malacarne et al., 2006). Another aspect to be considered is the deficient inter-diffusion of resin within the water-saturated demineralized dentin leaving unprotected or poorly encapsulated collagen fibrils that could be slowly hydrolyzed by endogenous matrix metalloproteinases (MMPs) (Li et al., 2012; Mortazavi et al., 2012).

\footnotetext{
* Escola Superior da Amazônia, Belém, Brazil.

* Federal University of Maranhão, Maranhão, Brazil.

$*$ Federal University of Pará, Belém, Brazil.

**** Department of Restorative Dentistry, Dental School, Federal University of Pará, Belém, Brazil.
} 
In that sense, the addition of hydrophobic monomers to the adhesive systems could improve the durability of resin-dentin bonds (Nishitani et al., 2006). Question is, how to seep water-insoluble hydrophobic monomers in a naturally moist substrate?

Ethanol-wet bonding is an in vitrotechnique developed for the application of etch-and-rinse adhesives (Pashley et al., 2007). Through this technique, the water within the acid-etched dentin is replaced by absolute ethanol, a polar solvent with less hydrogen bonding capacity than water, avoiding the collapse of the interfibrillar spaces within the collagen matrix (Li et al.; Sadek et al., 2007b; Kim et al., 2010).

As the ethanol-saturated dentine is less hydrophilic, it is more compatible with hydrophobic resin monomers (Sadek et al., 2010a), preventing phase separation (Breschi et al., 2008; Van Meerbeek et al., 2010). Moreover, the ethanol shrinks the diameter of collagen fibrils more than it shrinks the volume of the matrix; consequently, the interfibrillar spaces of ethanolsaturated dentin are larger than those of watersaturated dentin, allowing more hydrophobic resin infiltration (Hosaka et al.; Kim et al.).

Several laboratory researches have shown a promising performance of ethanol-wet bonding technique (EWBT) to improve resin-dentin bonding durability (Sadek et al., 2010a; Li et al.), but there are few clinical data about this matter (Mortazavi et al.; Araújo et al., 2013; Kuhn et al., 2015). Besides, some unfavorable aspects are mentioned in the literature, such as the time consuming technique, which demands several sequential steps, making the clinical procedure not attractive (Souza Júnior et al., 2015).

The objective of this RCCT was to evaluate and compare the clinical performance as regards retention and marginal adaptation/staining up to 18 months of restorations placed in NCCLs using the simplified EWBT and compare with a Three-Step Etch and Rinse (TSER) and a One-Step Self-Etching (OSSE) techniques. The null hypothesis to be tested is there are no differences in clinical performance among the three adhesives strategies after 18 months.

\section{MATERIAL AND METHOD}

Randomized Controlled Clinical Trial (RCCT). Seventeen patients ( 11 women and 6 men) aged from
23 through 54, employees and students of Federal University of Pará (UFPA) participated in this RCCT. All of them were instructed on the conditions and objectives of the study, and then signed informed consent forms and authorizations to participate in this investigation, which had been reviewed and approved by the Ethics Committee on Investigations Involving Human Subjects at the Federal University of Pará (UFPA). This study was formulated following the main guidelines of the CONSORT Group (Consolidated Standards of Reporting Trials) and was registered at the ISRCTN (International Standard Randomized Controlled Trial Number) 00627732.

The following criteria were evaluated for selection: good oral hygiene, no periodontal disease and at least 3 NCCLs (inclusion criteria). Exclusion criteria were the presence of orthodontic appliances or partially removable prosthodontics, high caries risk (presence of three or more active caries lesions), level 2 or 3 bruxism and patients who did not accept the conditions of the project.

Restorative Procedures. Ninety-three NCCLs (31 for each group) were restored by one experienced operator using three types of adhesive protocols. Table I summarizes the most important information on the materialsand details of methodology. All restorations were placed under relatively dry conditions using gingival retraction cord, cotton rolls and saliva ejector. No undercuts, grooves or bevels were performed, just a slight roughening of the surface with a 3118 diamond bur (K.G. Sorensen, Alphaville, Sao Paulo, Brazil).

Each adhesive system was randomly allocated to one of the randomized cervical lesions until be three groups were present in the same subject in equal amounts.

The hydrophobic primer used in the EWBT was prepared by diluting $2 \mathrm{~mL}$ step 3 of SBMP (3M ESPE) with corresponding to 10 mass percent absolute ethanol.

After adhesive system application, all NCCLs were restored with a nanofilled composite resin (Z350 XT, 3M ESPE, St.Paul, MN USA). Each increment was light-cured for 40 s using a LED source (D-2000; DMC, Joinvile, SC, Brazil) with an output of $1.100 \mathrm{~mW} / \mathrm{cm} 2$. After polymerization all restorations were finished and polished with \#3195 fine diamond burs (K.G. Sorensen), and rubber points (Dentsply/Caulk, Milford, DE, USA). 
Clinical evaluation. The restorations were evaluated at baseline, 6, 12 and 18 months by two calibrated examiners who did not participate in restorative procedures and were fully blinded regarding experimental groups. The modified US Public Health Service guidelines (USPHS), also known as the modified "Ryge criteria" (Table II), were used to evaluate the following outcomes: retention (kappa $=1.00)$, staining and marginal adaptation (kappa= 0.81)

Scanning Electron Microscopy (SEM). Eighteen human teeth that had NCCLs were collected and cleaned with periodontal curettes, and submitted to prophylaxis with pumice and water. No undercuts, grooves or bevels were performed, just a slight roughening of the surface with a \#3118 diamond bur (K.G. Sorensen). To perform the hybridization step the teeth were randomly divided into 3 groups (TSER, OSSE and EWBT) according to the adhesive protocol used. The adhesive application protocols were applied to each group according to Table I.

After hybridization, the NCCLs were restored with a nanofilled composite resin (Z350 XT, 3M ESPE).
Each increment was light-cured for $40 \mathrm{~s}$ using a LED source (D-2000, DMC) with an output of $1.100 \mathrm{~mW} /$ $\mathrm{cm} 2$ beyond finished and polished with \#3195 fine diamond burs (K.G. Sorensen), and rubber points (Dentsply).

The teeth were sectioned using a diamondimpregnate copper disc maintaining a margin around $3 \mathrm{~mm}$ of the limits by restoration. One half of the prepared teeth in each group were subjected to SEM, while the other half was stored in water for a period of 18 months.

Specimens were included into PVC discs containing acrylic resin, leaving exposed the proximal surfaces (mesial or distal). Thinning was performed by a wet grinding using 360 -grit $\mathrm{SiC}$ paper until the interface composite/cervical lesion was visible. The specimens were polished, etched with $35 \%$ phosphoric acid for $5 \mathrm{~s}$ and rinsed with distilled water. They were subsequently fixed in $2,5 \%$ glutaraldehyde, rinsed with $0.2 \mathrm{M}$ sodium cacodylate buffered at $\mathrm{pH} 7,4$ (three baths of 20 min each) then, dehydrated in alcohol. The specimens were dried by immersion in pure

Table I. Adhesives systems, composition e application techniques

\begin{tabular}{|c|c|c|c|}
\hline \multirow[t]{2}{*}{ GROUP } & \multicolumn{3}{|c|}{ Adhesive Systems } \\
\hline & TSER & OSSE & EWBT \\
\hline $\begin{array}{l}\text { Material } \\
\text { Composition }\end{array}$ & $\begin{array}{l}\text { Adper Scotchbond Multi- } \\
\text { Purpose1 } 1 \text { SBMP) } \\
\text { Primer: HEMA**, polyalk enoic } \\
\text { acid polymer, water }\end{array}$ & $\begin{array}{l}\text { Adper Easy One2* } \\
\text { HEMA, methacrylate phosphoric } \\
\text { esters; } 1,6 \text { hexanediol } \\
\text { dimethacrylate }\end{array}$ & $\begin{array}{l}\text { Ethanol solutions + "Hydro phobic primer" } \\
+ \text { pass } 3 \text { of SBMP } \\
\text { Ethanol } 50 \%: 50 \% \text { vol. absolute ethanol } \\
\text { and } 50 \% \text { vol. distilled water }\end{array}$ \\
\hline & $\begin{array}{l}\text { Adhesive: Bis-GMA }{ }^{* * *} \text {, } \\
\text { HEMA, tertiary a mines, } \\
\text { iniciator }\end{array}$ & $\begin{array}{l}\text { Vitrebond }{ }^{\mathrm{TM}} \text { Copolymer silica filler, } \\
\text { ethanol, water and initiators }\end{array}$ & $\begin{array}{l}\text { Ethanol } 100 \%: 99,8 \% \text { ethyl alcohol and } \\
0,2 \% \text { water } \\
\text { Hydrophobic primer: Bis-GMA, HEMA, } \\
\text { tertiary amines, iniciator, } 10 \% \text { mass. } \\
\text { ethan ol } 100 \%\end{array}$ \\
\hline $\begin{array}{l}\text { Adhesive } \\
\text { Technique }\end{array}$ & $\begin{array}{l}\text { 1- etching of enamel and } \\
\text { dentin for } 30 \text { and } 15 \mathrm{~s}, \\
\text { respectively, with } 37 \% \\
\text { phosphoric acid gel and } \\
\text { rinsing by air-water spraying } \\
\text { for } 30 \mathrm{~s}\end{array}$ & $\begin{array}{l}\text { 1- dentin washing and blotting with } \\
\text { absorbent paper to keep the surface } \\
\text { visibly moist }\end{array}$ & $\begin{array}{l}\text { 1- etching of enamel and dentin for } 30 \\
\text { and } 15 \mathrm{~s} \text {, respectively, with } 37 \% \\
\text { phosphoric acid gel and rinsing with an } \\
\text { air-water spray for } 30 \mathrm{~s}\end{array}$ \\
\hline & $\begin{array}{l}\text { 2- dentinblotting with } \\
\text { absorbent paper to keep the } \\
\text { surface visibly moist } \\
\text { 3- application of primer for } 20 \\
\mathrm{~s} \text { and air-drying for } 30 \mathrm{~s} \\
\text { 4- application of adhesive and } \\
\text { light curing for } 20 \mathrm{~s}\end{array}$ & $\begin{array}{l}\text { 2- application of Easy One adhesive } \\
\text { for } 20 \mathrm{~s} \text {, air-drying for } 5 \mathrm{~s} \text { and light } \\
\text { curing for } 20 \mathrm{~s}\end{array}$ & $\begin{array}{l}\text { 2- blotting of dentin with absorbent paper } \\
\text { to keep the surface visibly moist } \\
\text { 3- application of } 50 \% \text { ethanol for } 10 \mathrm{~s} \\
\text { and allowed to sit for } 10 \mathrm{~s} \\
\text { 4- application of } 100 \% \text { ethanol for } 10 \mathrm{~s} \\
\text { and allowed to sit for } 10 \mathrm{~s} \\
5 \text { - application of a "hydrophobic primer" } \\
\text { for } 20 \mathrm{~s} \text { and air-drying for } 30 \mathrm{~s} \\
\text { 6- application of the SBMP adhesive } \\
\text { (step 3) and light curing for } 20 \mathrm{~s}\end{array}$ \\
\hline
\end{tabular}

1= 3M ESPE, St Paul, MN, USA. 2=3M ESPE, Seefeld, Germany $\quad *=$ Adper Easy Bond in the USA. $\quad$ **= HEMA: 2-hydroxyethil methacrylate ${ }^{* * *}=$ Bis-GMA: bisphenol A diglycidyl ether dimethacrylate 
BARROS, T. A. F.; DA ARAÚJO, J. F.; BRAGA, E. M. F.; SILVA E SOUZA, R. P. A.; LORETTO, S. C. \& SOUZA JÚNIOR, M. H. S. Ethanol-wet bonding technique: 18-month clinical evaluation. Int. J. Odontostomat., 10(2):267-276, 2016.

Table II. Modified US Public Health Service guidelines (USPHS). Source: Kubo et al. (2006).

\begin{tabular}{|c|c|c|c|}
\hline \multirow[t]{2}{*}{ Criteria } & \multicolumn{2}{|c|}{ Rating scale } & \multirow[t]{2}{*}{ Description } \\
\hline & Acceptable & Unacceptable & \\
\hline \multirow[t]{2}{*}{ Retention } & Alpha $(A)$ & - & Restoration is present \\
\hline & - & Charlie (C) & Restoration is partially or totally lost \\
\hline \multirow[t]{3}{*}{ Marginal Adaptation } & Alpha (A) & - & Undetectable margin \\
\hline & Bravo (B) & - & Slight detectable gap \\
\hline & - & Charlie (C) & Obvious crevice or fracture \\
\hline \multirow[t]{3}{*}{ Marginal Staining } & Alpha (A) & - & No marginal discoloration \\
\hline & Bravo (B) & - & Superficial staining (removable, usually localized) \\
\hline & - & Charlie (C) & Deep staining (no-removable, generalized) \\
\hline
\end{tabular}

hexamethyldisilazane (HMDS) for $10 \mathrm{~min}$. The HDMS was allowed to evaporate for $15 \mathrm{~min}$ in air before specimens were sputter-coated in gold palladium. The specimens were examined and photographed with a SEM Quanta 600FEG (FEI Company).

Statistical Analysis. The data obtained from this RCCT were plotted, and differences among the adhesive techniques at each evaluated period were analyzed by the Fisher's exact test and Kruskal-Wallis test for retention and staining/marginal adaptation, respectively. Conversely, in order to visualize possible differences among each adhesive protocol along 18 months, the Wilcoxon's test was applied for marginal adaptation/staining criteria and the Cochran's test for retention. The survival analysis for retention criterion and the overall clinical success percentage in each group over time (baseline, 6, 12, 18 months) was performed using a log-rank test. The significance level considered to all tests was $5 \%$.

\section{RESULTS}

Randomized Controlled Clinical Trial (RCCT).The recall rates were $100 \%$ within all evaluated periods. The intergroup analysis revealed no significant differences $(p>0.05)$ for up to 6,12 and 18 months for all the assessed criteria (Table III). The survival analysis showed that although the retention rate in OSSE was lower (83.87 \%) when compared with TSER and EWBT $(93.55 \%)$, that difference was not significant $(p>0.05)$ after 18 months (Fig. 1). Although the overall clinical successes percentages at 18 months were lower in OSSE $(80.64 \%)$ compared with TSER $(90.32 \%)$ and EWBT $(93.55 \%)$, no significant difference was observed among groups (Fig. 2).

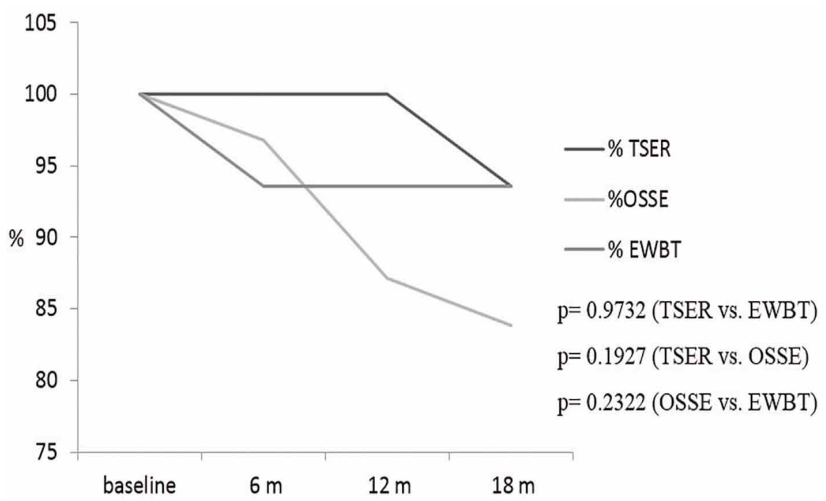

Fig. 1. Survival curves to retention criterion for each adhesive system for up to 18 months.

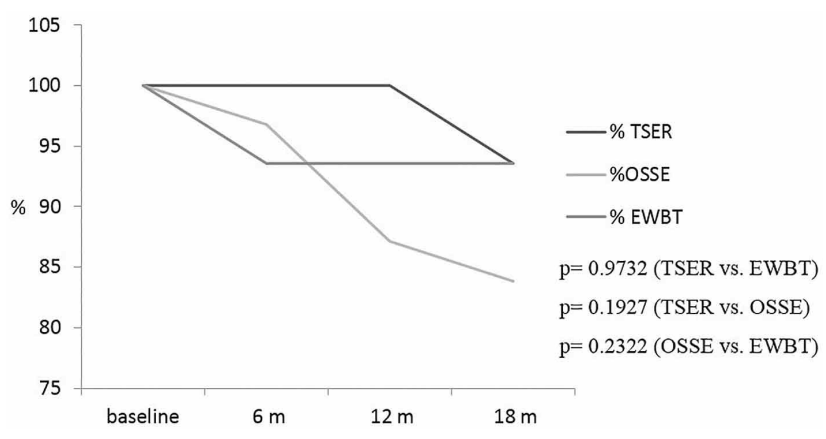

Fig. 2. Overall clinical success for each adhesive protocol for up to 18 months.

The overtime evaluation for each adhesive technique showed an increasing percentage of score $B$ between baseline and 18 months for marginal adaptation (TSER: $3.45 \%$, OSSE: $26.92 \%$ and EWBT: $10.34 \%)$, beyond, in the OSSE group, one restoration was scored in C (3.8\%). That difference was statistically significant $(p \leq 0.05)$ in marginal adaptation for OSSE group (Table IV). 
BARROS, T. A. F.; DA ARAÚJO, J. F.; BRAGA, E. M. F.; SILVA E SOUZA, R. P. A.; LORETTO, S. C. \& SOUZA JÚNIOR, M. H. S. Ethanol-wet bonding technique: 18-month clinical evaluation. Int. J. Odontostomat., 10(2):267-276, 2016.

Table III. Intergroup clinical evaluation for each criterion at 6, 12 and 18 months. Number of restorations rated / total number of restorations.

\begin{tabular}{|c|c|c|c|c|}
\hline Criteria & Adhesive System Group & $18 \mathrm{mor}$ & & \\
\hline & & $A$ & $B$ & $\mathrm{C}$ \\
\hline Retention & TSER (G1) & $29 / 31$ & - & $2 / 31$ \\
\hline & OSSE (G2) & $26 / 27$ & - & $1 / 27$ \\
\hline & EWBT(G3) & $29 / 29$ & - & 0 \\
\hline & & $p=1.000(G 1 \times G 2)^{a}$ & & \\
\hline & & $p=0.4821(G 2 \times G 3)^{a}$ & & \\
\hline & & $p=0.4921(G 1 \times G 3)^{a}$ & & \\
\hline Marginal Adaptation & TSER (G1) & $27 / 29$ & $1 / 29$ & $1 / 29$ \\
\hline & OSSE (G2) & $18 / 26$ & $7 / 26$ & $1 / 26$ \\
\hline & EWBT(G3) & $26 / 29$ & $3 / 29$ & 0 \\
\hline & & $p=0.1363(G 1 \times G 2)^{b}$ & & \\
\hline & & $p=0.1905(G 2 \times G 3)^{b}$ & & \\
\hline & & $p=0.8523(G 1 \times G 3)^{b}$ & & \\
\hline Marginal Staining & TSER (G1) & $19 / 29$ & $10 / 29$ & 0 \\
\hline & OSSE (G2) & $22 / 26$ & $4 / 26$ & 0 \\
\hline & EWBT(G3) & $26 / 29$ & $6 / 29$ & 0 \\
\hline & & $p=0.2278$ & & \\
\hline
\end{tabular}

$a=$ Fisher's exact test. $b=$ Kruskal-Wallis test. $p \leq 0.05$.

Table IV. Intra-group analysis and respective p-value to each criterion over 18 months.

\begin{tabular}{llll}
\hline Group & Retention & Marginal Adaptation & Marginal Staining \\
\hline & $\mathrm{B} \times 6 \mathrm{M} \times 12 \mathrm{M} \times 18 \mathrm{M}$ & $\mathrm{B} \times 18 \mathrm{M}$ & $\mathrm{B} \times 18 \mathrm{M}$ \\
TSER & $\mathrm{p}=0,1116^{\mathrm{a}}$ & $\mathrm{p}=0,1797^{\mathrm{b}}$ & $\mathrm{p}=0,0051^{\mathrm{b}^{*}}$ \\
OSSE & $\mathrm{p}=0,0101^{\mathrm{a}^{*}}$ & $\mathrm{p}=0,0117^{\mathrm{b}^{*}}$ & $\mathrm{p}=0,0679^{\mathrm{b}}$ \\
EWBT & $\mathrm{p}=0,1116^{\mathrm{a}}$ & $\mathrm{p}=0,1088^{\mathrm{b}}$ & $\mathrm{p}=0,0277^{\mathrm{b}^{*}}$ \\
\hline
\end{tabular}

$a=$ Cochran's test. $\quad b=$ Wilcoxon's test. $\quad *=p \leq 0.05$

In addition, an increasing percentage of score $B$ was also observed after 18 months for marginal staining (TSER: $34.48 \%$, OSSE: $15.38 \%$ and EWBT: $20.68 \%$ ). These differences were significant in TSER and EWBT groups when compared to baseline.

The OSSE group showed significant differences for retention criterion after 18 months. Table 4 shows the p-values of all groups for each criterion evaluated for up to 18 months.

SEM Observations. Representative SEM micrographs of the adhesive/dentin interface of specimens from each group are shown in Figure 3. The SEM images of non-aged specimens subjected to SEM showed satisfactory adhesive-infiltrated layer for all groups (Fig. 3 A1-2, B1-2, C1-2).

The images obtained from aged specimens showed a well-defined and continuous hybrid layer for TSER and EWBT interfaces. From a closer view, an adequate sealing between the adhesive tags and tubule walls was observed (Fig. 3 - A3-4 and C3-4). In the OSSE specimen was observed an effective sealing of dentine in some areas (Fig. 3 B3), nonetheless, compromised interface was also observed, depicting a lack of adhesive interdifusion (Fig. 3 B4).

\section{DISCUSSION}

In adhesive dentistry, there is a consensus according to which the stability of resin-dentin bonds is questionable (Breschi et al.). Therefore, manufacturers and researchers were seeking a way to improve the adhesive systems, aiming to increase the stability and longevity of the adhesive interface created by these systems. 


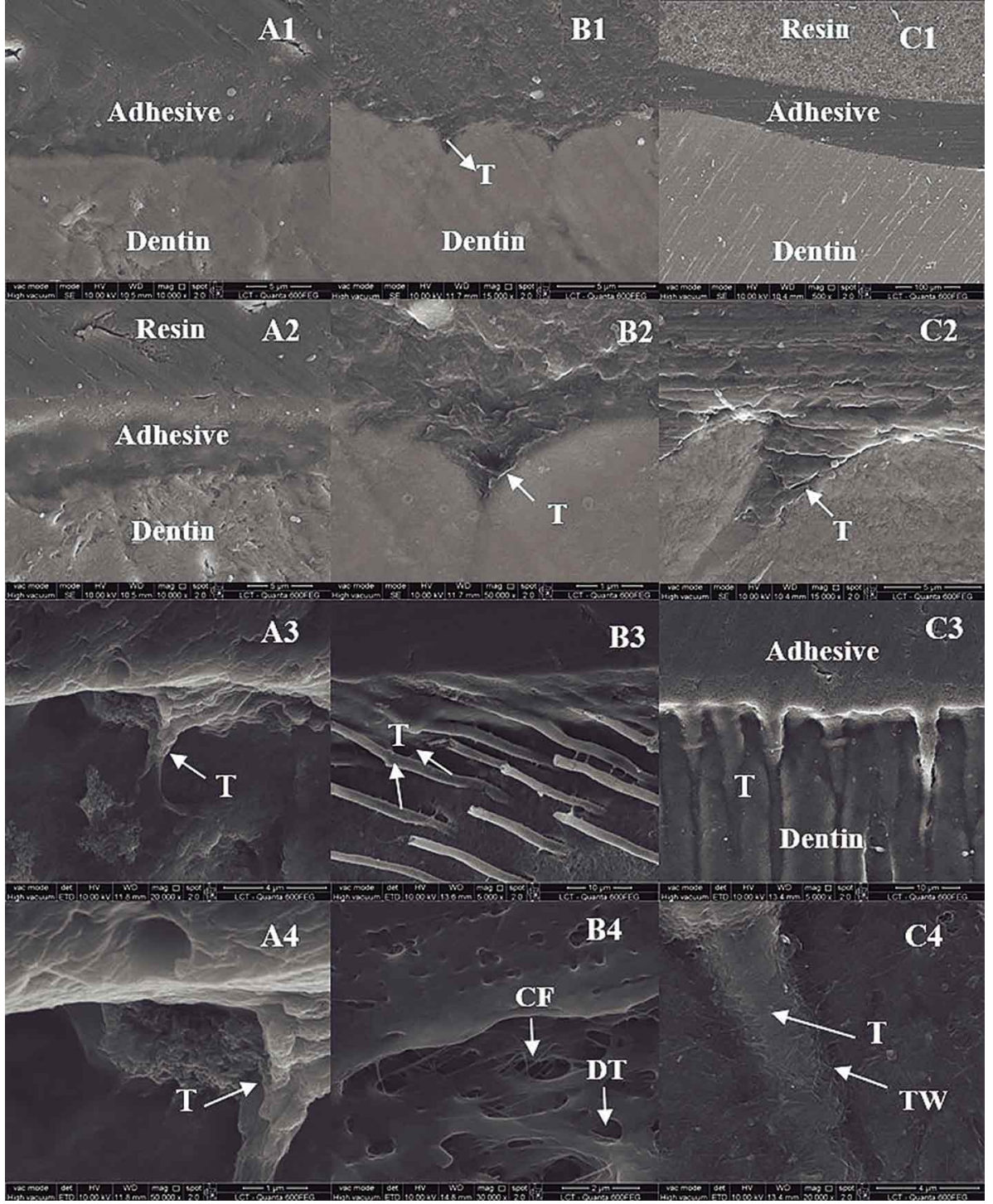

Fig. 3. SEM micrographs of the adhesive/dentin interfaces.
In this study, retention was the primary outcome considered, and represents the most obvious sign of restoration failure (Heintze et al., 2010). The marginal adaptation and staining were also included as evaluation criteria in this research. Despite the high disagreement rate reported among examiners during evaluation measurement, Chee et al. stated that the marginal failure of restoration is a common reason for the replacement and repair of adhesive procedures. In a comparative clinical and laboratory evaluation, Kuhn et al., observed better behavior of the EWBT regarding marginal sealing, showed through nanoleakage tests.

Other
mentioned in clinical
evaluation systematic reviews are that the minimum evaluation period should be 18 months. Besides, the total rate recall at 18 months should be above $75 \%$ (Heintze et al., 2010; Chee et al.). Both features were present in this RCCT.
The RCCT is the most careful and precise study design when the evaluation of materials, drugs, techniques and protocols as far as the health sciences is concerned. In dentistry, clinical evaluation of materials and techniques are currently performed, and adhesive procedures are one of the most clinically evaluated in restorative field. The preferred situation for restorative materials/techniques clinical evaluation is the NCCLs. This type of cavity offers no mechanical retention form, thus the stability of the restoration depends basically on the bonding quality, and an adhesive failure will result in loss of restoration (De Munk et al.; Van Meerbeek et al.; Heintze et al., 2010; Chee et al., 2012).
According to Malacarne et al. and Ayar et al. (2012), the current generation of dentin adhesives has been criticized due their high hydrophilic and waterabsorbing properties, which may over time compromise the mechanical properties of the hybrid layer.

The goals of chemical dentin dehydration using ethanol solutions have been increasingly considered. This technique is employed to chemically dehydrate the exposed collagen in order to avoid their collapse (Sadek et al., 2007a; Ayar et al.). The ability to reduce the collagen fibril diameter has been demonstrated, thus increasing the interfibrillar spaces in hybrid layer (Hosaka et al.; Li et al.; Kim et al.; Ayar et al.; Sadek et 
al., 2010b). Ethanol is less capable of breaking spontaneously to form hydrogen bonding with adjacent collagen fibrils due to its reduced Hoy's solubility parameter values (dh). Thus the replacement of water by the ethanol solution in demineralized dentin induces $15-17 \%$ shrinkage in the collagen matrix. The increased ability of the ethanol-saturated collagen fibril to form interpeptide bonds also stiffens the collagen matrix by reducing the plasticizing effect of water (Sadek et al., 2007b).

The second goal of the EWBT is the replacement of ethanol within collagen matrix for less hydrophilic monomer blends. Hydrophobic monomers are usually miscible in ethanol. The ethanol-saturated collagen matrix creates favorable conditions for methacrylate (such as Bis-GMA) to diffuse into interfibrillar spaces, hence an optimal encapsulation of collagen with adhesive resin is obtained, preventing the harmful action of endogenous matrix metalloproteinases (MMPs). Indeed, the replacement of water by ethanol also removes the hydrolytic medium for the functioning of MMPs (Hosaka et al.; Li et al.; Sadek et al., 2010b).

Some other advantages of EWBT have been cited, such as a reduction in the number of nanometersized channels produced by residual water on collagen fibrils, which decreases the micropermeability (Grégoire et al., 2013; Sauro et al., 2009b). The phase separation within collagen matrix may also be reduced due to the drop in the residual water content (De Munk et al.; Sadek et al., 2010b).

In this sense, several laboratory assignments have shown encouraging results regarding EWBT (Hosaka et al.; Sadek et al., 2010a; Li et al.; Nishitani et al.; Ayar et al.; Grégoire et al.; Sauro et al., 2009b). Clinical trials are nevertheless scarce, especially RCCTs which included EWBT as experimental group.

One of the criticisms to the clinical approach is the high number of steps, mostly during the dentin saturation. The protocol, according to the laboratory evaluations, suggests the use of increasing concentrations of ethanol solutions, which may take around three and a half minutes to be completed (Sadek et al., 2010a). That protocol may impair clinical applications. Proposal of simplified approaches, using only one application of $100 \%$ ethanol (Mortazavi et al.) and two sequential applications of $50 \%$ and 100 $\%$ of ethanol (Araújo et al.) showed no differences when compared to the water-wet bonding techniques
For this study, a simpler clinical protocol for ethanol dentin saturation was adopted. Only two ethanol solutions concentrations (50\% and $100 \%$ ) were applied for $10 \mathrm{~s}$ and left undisturbed for another 10 seconds. This procedure reduced the entire time for dentin saturation to $40 \mathrm{~s}$, which could be considered clinically reasonable. This reduction in the number of ethanol solutions concentration is somehow supported by the literature. There are quite a few published laboratory studies in which simpler ethanol application protocols were used to dehydrate etched dentin ( $\mathrm{Li}$ et al.; Ayar et al.; Grégoire et al.).

In this particular study, at an 18-month evaluation period, the recall attendance was total $(100 \%)$ and the comparison among groups, regarding retention, marginal adaptation and staining, showed no significant differences (Table III). Indeed, when the primary outcome (retention) was analyzed independently, the survival curve (Fig. 1) did not reveal differences among adhesive approaches along the total evaluation period (18 months). However, it is possible to note variations in the percentage of retention. The restorations bonded with TSER, and EWBT exhibited the same percentage of remaining restorations over 18 months (93.55\%) versus $83.87 \%$ of the OSSE group. On the other hand, when the OSSE group was individually evaluated for retention criterion at 18 months, it showed a significant difference $(p=0.0101)$ when compared to baseline (Table IV). In Heintze et al. (2010), meta-analysis study was stated that the one-step self-etching systems showed worst results when longevity was a concern, whereas the three-step etch-and-rinse exhibited better and more predictable outcomes.

Van Meerbeek et al., and Peumans et al. (2007), reported that one factor causing NCCLs is the flexure at the tooth cervix. In addition, they suggested it is reasonable to accept that similar stress is imposed to the restored NCCLs, thereby promoting dislodgement of the restoration. Considering these affirmations, the adhesive ability of the system is of fundamental importance for restoration stability. Another feature would be the composite stiffness. Higher elastic modulus implies in higher dislodgement rates of NCCLs. However, the Z-350 XT, used here, presents high elastic modulus and was the only restorative material employed. Thereby, the adhesive strength seems to have greater influence on this feature.

The SEM images related to TSER and EWBT showed good sealed interfaces (Fig. 3- A1-4, C1-4). It is possible to note, in aged and non-aged specimens, 
an intimate contact between the resin and dentin, especially when the interface between resin tags and tubular dentin was observed under high magnification. At Figure 3- C3-4, all the hybrid layer components are intact, depicting a very good sealed interface.

Despite the absence of statistical significance, when retention was compared among groups, it was possible to identify a slight discrepancy in the percentage of remaining restorations at an 18-month evaluation period (Fig. 1). When the OSSE aged specimens were observed, some presented good sealed interfaces (Fig. 3- B3). However, at some other SEM images, as Figure 3-B4, a lack of adhesive inter-diffusion can be suggested, once no resin tags are seen and dentin tubules as well as exposed collagen were visualized.

When each group was individually analyzed at an 18-month clinical evaluation (Table IV), the OSSE presented significant differences for marginal adaptation $(p=0.0117) .26 .5 \%$ of the remaining restorations were scored $B$ and one (3.8\%) classified as $\mathrm{C}$. The stress imposed to NCCls restorations could also be related to marginal degradation (Grégoire et al.). Therefore, adhesive skills of the systems would also play an important role on this criterion. Van Landuyt et al. (2011), stated in a 3-year clinical evaluation of a mild HEMA-free one step self-etching system adhesive that $70 \%$ of the restorations presented some degree of marginal degradation at enamel margins and $32 \%$ at dentin. The OSSE group restorations presented the worst marginal adaptation behavior at 18-months evaluations. Studies have shown that the quality of the bonded interface, as well as the bond strength provided by mild self-etch adhesives can be considerably improved by the adjunctive selective acid-etching of the enamel margins (Van Landuyt et al.; Moretto et al., 2013). Mild self-etch adhesives are not aggressive enough, and micromechanical retention seems to be much more important for enamel bonding efficacy than the potential additional chemical bonding provided by specific functional monomers (Van Landuyt et al.). In addition, Moretto et al., reported a slight tendency towards a higher incidence of small marginal defects and the presence of HEMA in adhesive solution, due to its hydrophilic characteristics. Therefore, the adhesive layer is more prone to water uptake and marginal degradation afterwards. These two features, mild aggressiveness and the presence of HEMA are present in OSSE system.
At 18 months, $34.48 \%$ of the TSER were scored as B, while in the EWBT $20.68 \%$ received such category. These results were significant compared to baseline (Table IV). Heintze et al. (2011) reported that clinical trials suggested that the presence of marginal staining is dependent, to a certain extent, on the marginal adaptation of the restoration. They state that marginal staining can occur due to small fractures of the material or overhangs at margins and the following microleakage. However, in the present clinical study, ten restorations of TSER group were scored as B for marginal staining. On the other hand, just one of them was classified as $\mathrm{B}$ for marginal adaptation. These puzzling results can be explained as a patient factor (Van Landuyt et al.; Moretto et al.). The preference of food and beverage, smoking and tooth brushing habits may play a role in marginal staining. Indeed, it was reported (Kubo et al., 2006) that these differences in the relationship adaptation versus staining were common during the first evaluation periods, and seem to be more even at latter periods.

Regarding retention there were no differences among groups along the 18-month evaluation periods. The same conclusion can be attributed to marginal adaptation/staining for all groups. Therefore, the three clinical protocols presented similar overall clinical successes during the evaluation periods. On the other hand, the intra-group analysis showed worse results for retention and marginal adaptation in OSSE group and for marginal staining in groups TSER/EWBT when 18-month result was compared to baseline.

Up to 18-month evaluation the simplified EWBT used in this study showed good clinical results, similar to those observed to the TSER, which is considered gold standard.

These 18-month results, when a simplified EWBT was employed, can so far be clinically accepted, because they were comparable to those observed of the gold standard TSER. However, longer observation periods will be necessary, considering the major alleged advantage for the EWBT, that is to produce less hydrophilic interfaces.

\section{ACKNOWLEDGEMENTS}

The authors would like to thank the volunteers participation. 
BARROS, T. A. F.; DA ARAÚJO, J. F.; BRAGA, E. M. F.; SILVA E SOUZA, R. P. A.; LORETTO, S. C. \& SOUZA JÚNIOR, M. H. S. Técnica de adhesión húmeda en etanol: evaluación clínica a los 18 meses. Int. J. Odontostomat., 10(2):267-276, 2016.

RESUMEN: El propósito de este ensayo clínico aleatorizado fue evaluar, durante 18 meses, el éxito clínico de las restauraciones realizadas por la técnica de adhesión húmeda en etanol (TAHE) en comparación con las técnicas de grabado independiente de tres pasos (GTP) y de autograbado de un paso (AUP). Un solo operador, especializado en odontología restaurativa, realizó sobre 17 pacientes 93 restauraciones en lesiones cervicales no cariosas (31 para cada grupo). Los diferentes protocolos adhesivos se distribuyeron aleatoriamente en las lesiones cervicales hasta que los tres grupos estuviesen presentes en el mismo paciente y en cantidades iguales. Las restauraciones fueron evaluadas a los 6, 12 y 18 meses, por dos examinadores calibrados y que no participaron del procedimiento restaurador. Las directrices modificadas del Servicio de Salud Pública de Estados Unidos (SSPEU) fueron la base para las evaluaciones de las siguientes variables: retención (kappa $=1,00)$, adaptación y decoloración marginal $(k a p p a=0,81)$. Estas variables fueron analizadas mediante la prueba exacta de Fisher y Kruskal-Wallis, respectivamente. No se observó diferencia significativa entre los grupos después de 18 meses en las tres variables evaluadas $(p>0,05)$. El análisis intra-grupo hecho por la prueba de Cochran (para la retención) y la prueba de Wilcoxon (para la adaptación y decoloración marginal) revelaron diferencias significativas entre los intervalos de tiempo de la línea de base / 18 meses para la retención $(p=0,0101)$ y adaptación marginal en el grupo AUP $(p=0,0117)$, y para la decoloración marginal en los grupos GTP $(p=0,0051)$ e TAHE $(p=0,0277)$. El análisis de supervivencia para la retención, así como la comparación del éxito clínico de los protocolos adhesivos, fueron realizados con la prueba de log-rank, y no hubo diferencias significativas $(p>0,05)$ entre los grupos. No hubo diferencia en el éxito clínico de los tres protocolos adhesivos después de 18 meses.

PALABRAS CLAVE: dentina; adhesivos de dentina; ensayo clínico aleatorizado.

\section{REFERENCES}

Araújo, J. F.; Barros, T. A.; Braga, E. M.; Loretto, S. C.; Silva e Souza, P. A. \& Silva e Souza, M. H. One-year evaluation of a simplified ethanol-wet bonding technique: a randomized clinical trial. Braz. Dent. J., 24(3):267-72, 2013.

Ayar, M. K.; Yesilyurt, C.; Alp, C. K. \& Yildirim, T. Effect of ethanol-wet-bonding technique on resin-enamel bonds. J. Dent. Sci ., 9(1):16-22, 2014.

Breschi, L.; Mazzoni, A.; Ruggeri, A.; Cadenaro, M.; Di Lenarda, R. \& De Stefano Dorigo, E. Dental adhesion review: aging and stability of the bonded interface. Dent. Mater., 24(1):90-101, 2008.

Chee, B.; Rickman, L. J. \& Satterthwaite, J. D. Adhesives for the restoration of non-carious cervical lesions: a systematic review. J. Dent., 40(6):443-52, 2012.

De Munk, J.; Van Landuyt, K.; Peumans, M.; Poitevin, A.; Lambrechts, P.; Braem, M. \& Van Meerbeek, B. A critical review of the durability of adhesion to tooth tissue: methods and results. J. Dent. Res., 84(2):118-32, 2005.

Grégoire, G.; Sharrock, P.; Delannée, M. \& Delisle, M. B. Depletion of water molecules during ethanol wetbonding with etch and rinse dental adhesives. Mater. Sci. Eng. C Mater. Biol. Appl., 33(1):21-7, 2013.
Heintze, S. D.; Ruffieux, C. \& Rousson, V. Clinical performance of cervical restorations--a meta-analysis. Dent. Mater., 26(10):993-1000, 2010.

Heintze, S. D.; Thunpithayakul, C.; Armstrong, S. R. \& Rousson, V. Correlation between microtensile bond strength data and clinical outcome of Class $\mathrm{V}$ restorations. Dent. Mater, 27(2):114-25, 2011.

Hosaka, K.; Nishitani, Y.; Tagami, J.; Yoshiyama, M.; Brackett, W. W.; Agee, K. A.; Tay, F. R. \& Pashley, D. $\mathrm{H}$. Durability of resin-dentin bonds to water- vs. ethanolsaturated dentin. J. Dent. Res., 88(2):146-51, 2009.

Kim, J.; Gu, L.; Breschi, L.; Tjäderhane, L.; Choi, K. K.; Pashley, D. H. \& Tay, F. R. Implication of ethanol wetbonding in hybrid layer remineralization. J. Dent. Res., 89(6):575-80, 2010.

Kubo, S.; Kawasaki, K.; Yokota, H. \& Hayashi, Y. Fiveyear clinical evaluation of two adhesive systems in non-carious cervical lesions. J. Dent., 34(2):97-105, 2006.

Kuhn, E.; Farhat, P.; Teitelbaum, A. P.; Mena-Serrano, A.; Loguercio, A. D.; Reis, A. \& Pashley, D. H. Ethanolwet bonding technique: Clinical versus laboratory findings. Dent. Mater., 31(9):1030-7, 2015. 
Li, F.; Liu, X. Y.; Zhang, L.; Kang, J. J. \& Chen, J. H. Ethanol-wet bonding technique may enhance the bonding performance of contemporary etch-and-rinse dental adhesives. J. Adhes. Res., 14(2):113-20, 2012.

Malacarne, J.; Carvalho, R. M.; de Goes, M. F.; Svizero, N.; Pashley, D. H.; Tay, F. R.; Yiu, C. K. \& Carrilho, M. R. Water sorption/solubility of dental adhesive resins. Dent. Mater., 22(10):973-80, 2006.

Moretto, S. G.; Russo, E. M.; Carvalho, R. C.; De Munk, J.; Landuyt, K.; Peumans, M.; Van Meerbeek, B. \& Cardoso, M. V. 3-year clinical effectiveness of onestep adhesives in non-carious cervical lesions. $J$. Dent., 41(8):675-82, 2013.

Mortazavi, V.; Samimi, P.; Rafizadeh, M. \& Kazemi, S. A randomized clinical trial evaluating the success rate of ethanol wet bonding technique and two adhesives. Dent. Res. J. (Isfahan), 9(5):588-94, 2012.

Nishitani, Y.; Yoshiyama, M.; Donnelly, A. M.; Agee, K. A.; Sword, J.; Tay, F. R. \& Pashley, D. H. Effects of resin hydrophilicity on dentin bond strength. J. Dent. Res., 85(11):1016-21, 2006.

Pashley, D. H.; Tay, F. R.; Carvalho, R. M.; Rueggeberg, F. A.; Agee, K. A.; Carrilho, M.; Donnelly, A. \& GarcíaGodoy, F. From dry bonding to water-wet bonding to ethanol-wet bonding. A review of the interactions between dentin matrix and solvated resins using a macromodel of the hybrid layer. Am. J. Dent., 20(1):720, 2007.

Peumans, M.; De Munk, J.; Van Landuyt, K. L.; Kanumilli, P.; Yoshida, Y.; Inoue, S.; Lambrechts, P. \& Van Meerbeek, B. Restoring cervical lesions with flexible composites. Dent. Mater., 23(6):749-54, 2007.

Sadek, F. T.; Pashley, D. H.; Nishitani, Y.; Carrilho, M. R.; Donnelly, A.; Ferrari, M. \& Tay, F. R. Application of hydrophobic resin adhesives to acid-etched dentin with an alternative wet bonding technique. J. Biomed. Mater. Res. A, 84(1):19-29, 2007b.

Sadek, F. T.; Pashley, D. H.; Ferrari, M. \& Tay, F. R. Tubular occlusion optimizes bonding of hydrophobic resins to dentin. J. Dent. Res., 86(6):524-8, 2007a.

Sadek, F. T.; Castellan, C. S.; Braga, R. R.; Mai, S.; Tjäderhane, L.; Pashley, D. H. \& Tay, F. R. One-year stability of resin-dentin bonds created with a hydrophobic ethanol-wet bonding technique. Dent. Mater., 26(4):380-6, 2010a.

Sadek, F. T.; Braga, R. R.; Muench, A.; Liu, Y.; Pashley, D. H. \& Tay, F. R. Ethanol wet-bonding challenges current anti-degradation strategy. J. Dent. Res., 89(12):1499-504, 2010b.
Sauro, S.; Watson, T. F.; Mannocci, F.; Tay, F. R. \& Pashley, D. H. Prevention of water contamination of ethanolsaturated dentin and hydrophobic hybrid layers. J. Adhes. Dent., 11(4):271-8, 2009a.

Sauro, S.; Watson, T. F.; Mannocci, F.; Miyake, K.; Huffman, B. P.; Tay, F. R. \& Pashley, D. H. Two-photon laser confocal microscopy of micropermeability of resin-dentin bonds made with water or ethanol wet bonding. J. Biomed. Mater. Res. B Appl. Biomater., 90(1):327-37, 2009b.

Souza Júnior, M. H. S.; Ferreira, R. O.; Araújo, J. F.; Barros, T. A. F.; Braga, E. M. F. \& Loretto, S. C. Is the Ethanol Wet-bonding Technique a promising one? Int. J. Odontostomat., 9(3):463-8, 2015.

Van Landuyt, K. L.; Peumans, M.; De Munk, J.; Cardoso, M. V.; Ermis, B. \& Van Meerbeek, B. Three-year clinical performance of a HEMA-free one-step self-etch adhesive in non-carious cervical lesions. Eur. J. Oral Sci., 119(6):511-6, 2011.

Van Meerbeek, B.; Peumans, M.; Poitevin, A.; Mine, A.; Van Ende, A.; Neves, A. \& De Munck, J. Relationship between bond-strength tests and clinical outcomes. Dent. Mater., 26(2):e100-21, 2010.

Correspondence to:

Thaís Figueiredo Barros

Escola Superior da Amazônia

Belém, PA

BRAZIL

Email: thaisa_fig@hotmail.com

Received: 10-04-2016

Accepted: 18-07-2016 